\title{
Axonal Degeneration of the Peripheral Nerves and Postganglionic Anhidrosis in a Patient with Multiple Sclerosis
}

\author{
Hiroshi Saito, Kazuo Kobayashi, Hiroshi Mochizuki \\ and Tomonori IsHiI \\ Department of Neurology, Institute of Brain Diseases, \\ Tohoku University School of Medicine, Sendai 980
}

\begin{abstract}
Saito, H., Kobayashi, K., Mochizuki, H. and Ishis, T. Axonal Degeneration of the Peripheral Nerves and Postganglionic Anhidrosis in a Patient with Multiple Sclerosis. Tohoku J. Exp. Med., 1990, 162 (3), 279-291 — A 36-year-old woman had, since the age of 24 , numerous episodes of visual loss and spinal symptoms and signs at various levels, and was diagnosed as multiple sclerosis(MS). CSF myelinbasic-protein was increased. Neurological and electrophysiological investigations suggested the peripheral nerve involvement. Sural nerve biopsy performed about six years after the onset, revealed severe loss of both myelinated and unmyelinated fibers. Subsequently, histamine skin reaction was defective in the lower limbs. Tests on sudomotor and pupillary functions indicated deficits of both central and postganglionic sympathetic systems. Though we could not detect causative factors for the peripheral nerve lesions, our patient appears to be the first documented case of MS associated with axonal degeneration of the peripheral somatic and autonomic nervous systems. —— multiple sclerosis ; peripheral nerve ; axonal degeneration; postganglionic lesions
\end{abstract}

Multiple sclerosis (MS) has been generally known as a relapsing demyelinating disease exclusively affecting the central nervous system, but there is growing evidence that the peripheral nervous system may be also affected. Hasson et al. (1958) reported the presence of 6 patients of severe demyelination, and 6 patients of moderate demyelination of the peripheral nerves among 20 autopsied MS patients, and attributed the peripheral nerve lesions to malnutrition and the attending avitaminosis. However, this explanation has been regarded to be unlikely with the increasing number of MS patients associated with demyelinating or hypertrophic changes of the peripheral nerves (Schoene et al. 1977 ; Forrester and Lascelles, 1979; Weir et al. 1980 ; Lassmann et al. 1981; Ro et al. 1983; Tachi et al. 1985 ; Drake, 1987 ; Sanders and Lee 1987). Recently, Poser (1987) suggested a common pathogenetic mechanism for both central and peripheral

Received November 9, 1990 ; revision accepted for publication November 15, 1990.

Reprint requests: Dr. Hiroshi Saito, Department of Neurology, Institute of Brain Diseases, Tohoku University School of Medicine, 1-1 Seiryo-machi, Aoba-ku 980, Sendai Japan. 
demyelinating lesions in MS.

Here, we report a patient with MS showing the peripheral nerve impairment as well as postganglionic autonomic deficits. Unlike previously reported cases, her biopsied sural nerve showed severe loss of both myelinated and unmyelinated fibers.

\section{Case Report}

A 30-year-old woman in a wheel chair was first admitted to our hospital on December 23, 1982. She had been in excellent health and worked as a nurse until early June 1976, when she complained of numbness and weakness of the left hand, midthoracic back pain, and decreased sensation over the middle to lower trunk. Soon, she developed paralysis of the lower limbs and loss of vesical and rectal control. She was admitted to a local hospital and was treated with prednisolone. She gradually became ambulant and left the hospital on August 24, 1976. Slight numbness of hands and gurdle sensation over the middle trunk persisted. In July, 1978, she had anorexia, vomiting and a relapse of the midthoracic spinal symptoms, and was admitted to another hospital. The CSF contained $13 \mathrm{cells} / \mathrm{mm}^{3}$ and $169 \mathrm{mg} / 100 \mathrm{ml}$ of protein. Routine radiological examinations and spinal angiograms were normal. Her symptoms subsided within several weeks. In October 1978, she had acute loss of the left vision followed by reduction of the right vision. She was diagnosed as MS and treated with prednisolone. Visual acuity recovered, but insufficiently on the left side. During the subsequent 4 years, she had relapses of visual loss at least 3 times, and those of spinal symptoms of various levels more than 9 times. In April 1980, a compression fracture of the L1 and L4 vertebral bones was revealed.

On admission, general physical examinations were noncontributory apart from positive Lhermitte's sign and diffusely atrophied lower limbs. There was no orthostatic hypotension. She was alert, intelligent and cooperative. Right visual acuity was $20 / 20$ with full visual field, and the left, counting-fingers at $30 \mathrm{~cm}$ with central scotoma. The left optic disc was pale. Pupillary reactions were normal apart from Marcus-Gunn's sign on the left side. Other cranial nerves were intact. Muscle strength was 4/5 in the upper limbs and 2-3/5 in the lower limbs. Deep tendon reflexes were reduced in the upper limbs, normal in the left lower limb, and brisk in the right lower limb. Babinski's sign was positive on the right side. There were no cerebellar signs. She had dysesthesia and paresthesia below the C56 sensory level and anesthesia below the T11-12 level with loss of the bladder sensation and severe constipation.

Laboratory examinations showed moderate anemia; $\mathrm{RBC}: 382 \times 10^{4} / \mathrm{mm}^{3}, \mathrm{Hb}: 12.5$ $\mathrm{g} / 100 \mathrm{ml}$, and $\mathrm{Ht}: 36.8 \%$. Platelet count was $20.5 \times 10^{4} / \mathrm{mm}^{3}$. Total protein was $6.7 \mathrm{~g} /$ $100 \mathrm{ml}$. ESR was $6 \mathrm{~mm} / \mathrm{hr}$. CRP, RA and other serological tests including that for syphilis were negative. Other routine tests were within normal ranges. Oral glucose tolerance test $\left(75 \mathrm{~g}\right.$ ) was normal. The CSF on December 12,1982 contained one cell $/ \mathrm{mm}^{3}$ and $50 \mathrm{mg} / 100 \mathrm{ml}$ of protein. $\mathrm{x}$-Ray films of the chest and cervical spine were normal. Those of thoraco-lumbar spine showed compression fracture of the T11, L1 and L4 vertebral bones. EEG and brain CTs were normal.

She was treated with physiotherapy, prednisolone, ACTH and azathioprine. In March 1983, the lower limbs showed complete paralysis with normo-reflexia and indifferent plantar response. In May, orthostatic hypotension became apparent, leading sometimes to syncopal attacks, which gradually subsided. On June 2, 1983, she had another exacerbation showing horizontal gaze-evoked nystagmus, anisocoria, sensory deficits below C3-4, and weakness of the upper limbs. Deep reflex was brisk in the upper limbs. Patellar tendon reflex was normal, but Achilles reflex was bilaterally absent. The CSF taken two days later contained 121 cells $/ \mathrm{mm}^{3}, 179 \mathrm{mg} / 100 \mathrm{ml}$ of protein and $12.4 \mathrm{ng} / \mathrm{ml}$ of myelin basic protein (normal : less than 4.0). Oligoclonal IgG-band was not detected. Symptoms of the upper limbs 
gradually recovered, but the lower limbs remained flaccidly paralyzed. She repeated remissions and exacerbations chiefly of visual and spinal symptoms. She was transferred to another hospital in August 1985, and was readmitted in September 1987. Newly revealed neurological signs were the pale optic disc and central scotoma in the right eye, weakness and atrophy of the forearms and hand muscles with occasional fasciculations. Brain CT showed a low density area in the left centrum semiovale.

She was treated with plasmapheresis and prednisolone, but they could not prevent exacerbations. Since June 1988, sensation of the C2 cervical segment was impaired on the right side. She also complained of photophobia. Pupils which were $5.0-7.0 \mathrm{~mm}$ in diameter with occasional anisocoria, reacted sluggishly to light and on near vision. When she was tranferred again to the previous hospital, the right visual acuity was counting-fingers at 60 $\mathrm{cm}$, and the left, hand-movement at $30 \mathrm{~cm}$. Optic discs were pale, and the fields showed central scotoma, larger on the left side. The upper limbs were hyporeflexic and $2-3 / 5$ in strength. The lower limbs showed flaccid paralysis and areflexia. She had hypoesthesia below $\mathrm{C} 3$ on the right side, and below $\mathrm{C} 5$ on the left, and anesthesia below Th5.

After the initial admission, she showed moderate anemia(RBC : $362-441$ million $/ \mathrm{mm}^{3}$, $\mathrm{Hb}: 11.9-14.0 \mathrm{~g} / 100 \mathrm{ml}, \mathrm{Ht}: 36.4-41.8 \%$. Total protein remained in the range of $6.1-7.1$ $\mathrm{g} / 100 \mathrm{ml}$, though it decreased to $5.1-5.9 \mathrm{~g} / 100 \mathrm{ml}$ immediately after plasmapheresis. In June 1984, a small sacral decubitus developed, but healed within several weeks. Vitamin $\mathrm{B}$ complex and vitamin $\mathrm{C}$ were regularly administered. Other regular medications were carbamazepine $400 \mathrm{mg}$ per day for muscle cramps of upper limbs and sensory symptoms. Calcium-lactate, alfacalcidol, and cimetidine or ratinidine HCL were also given to prevent side-effects of prednisolone or ACTH. Azathioprine $50 \mathrm{mg}$ per day was given at intervals with a total dose of $16.5 \mathrm{~g}$ during 32 months. For occasional headaches and infections of the upper respiratory and urinary tracts, the following medications were given for brief periods ; ibuprofen $600 \mathrm{mg}$, nefenamic acid $450-600 \mathrm{mg}$, diclofenac sodium $75 \mathrm{mg}$, amoxicillin $1 \mathrm{~g}$ or cefaclor $1 \mathrm{~g}$ per day.

\section{Methods of Investigations and Results}

\section{Electrophysiological studies}

In March 1983, the motor nerve conduction velocity(MCV) was $64.0 \mathrm{~m} / \mathrm{sec}$ in the left ulnar nerve (UN), $63.7 \mathrm{~m} / \mathrm{sec}$ in the left median nerve (MN), $43.1 \mathrm{~m} / \mathrm{sec}$ in the left peroneal nerve, $38.6 \mathrm{~m} / \mathrm{sec}$ in the left posterior tibial nerve, and $22.9 \mathrm{~m} /$ sec in the right posterior tibial nerve. In the lower limbs, M-waves could be evoked only by stronger stimuli of $0.5-1.0 \mathrm{msec}$ in duration and $300 \mathrm{~V}$ in intensity. EMG revealed a decreased number of motor unit potentials (MUPs) of 13-16 msec in duration and polyphasic patterns in the flexor carpi ulnaris and extensor carpi radialis muscles on the left side. Both lower limbs showed no voluntary contraction. Fibrillation and fasciculation potentials were not seen.

In August 1983, MCV and the sensory nerve conduction velocity (SCV) of the right $\mathrm{MN}$ were $57.5 \mathrm{~m} / \mathrm{sec}$ and $70.0 \mathrm{~m} / \mathrm{sec}$, respectively. In the lower limbs, M-waves and sensory action potentials could not be evoked at this time and thereafter. In April 1984, MCV was $55.6 \mathrm{~m} / \mathrm{sec}$ in the right UN, $58.8 \mathrm{~m} / \mathrm{sec}$ in the left UN, $54.1 \mathrm{~m} / \mathrm{sec}$ in the right MN, and $62.1 \mathrm{~m} / \mathrm{sec}$ in the left MN. In December 1987, M-waves and sensory action potentials could not be evoked in the bilateral UNs. MCV of the MN was $58.0 \mathrm{~m} / \mathrm{sec}$ on the right, and $64 \mathrm{~m} / \mathrm{sec}$ on the left. $\mathrm{SCV}$ of the MN was $71.0 \mathrm{~m} / \mathrm{sec}$ on the right and $64.1 \mathrm{~m} / \mathrm{sec}$ on the left. EMG 

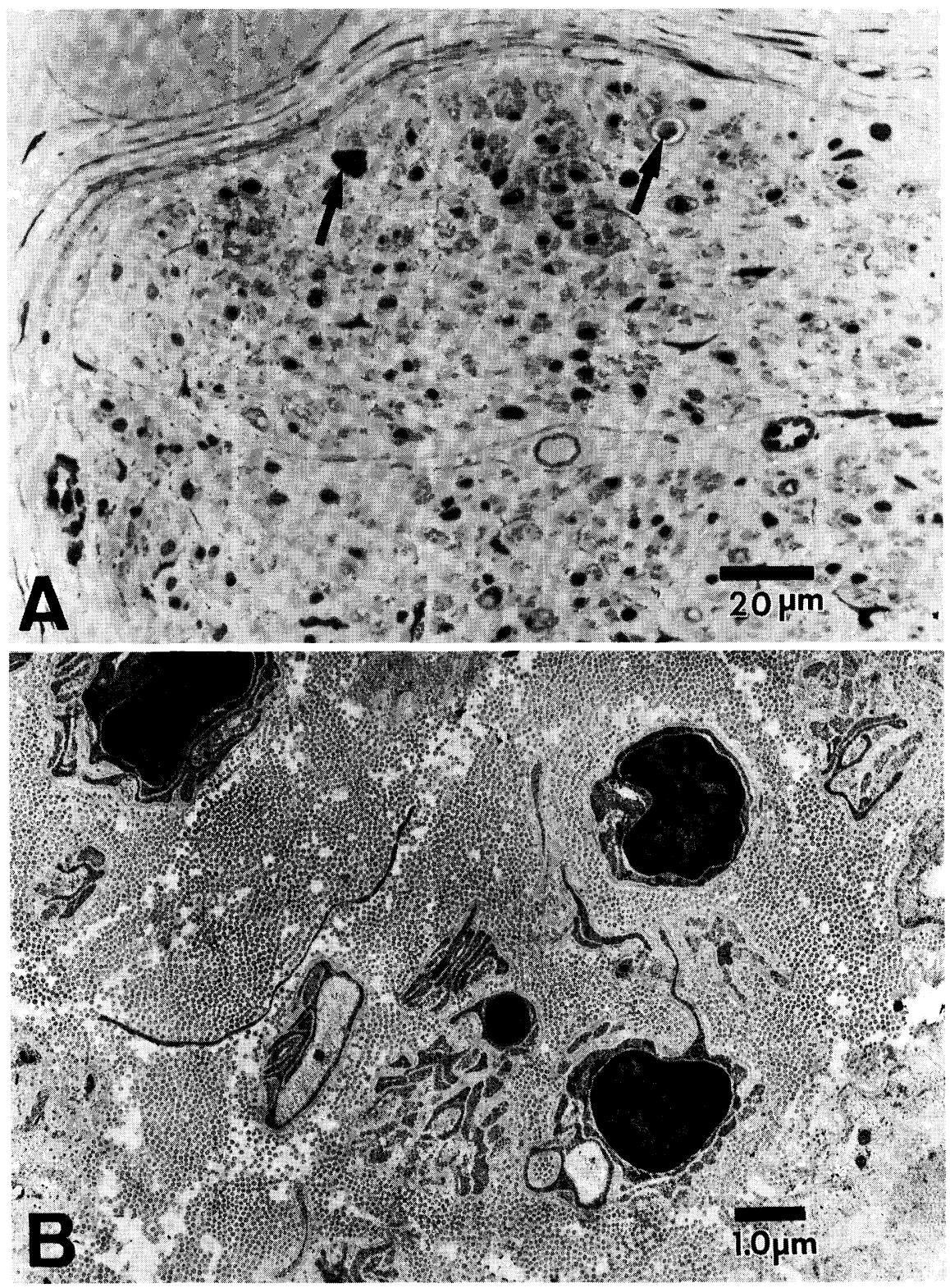

Fig. 1. A : The left sural nerve showing almost total loss of myelinated fibers and a few myelin ovoids (arrows). Toluidine-blue. $(\times 200)$, B : Electronmicroscopically, the number of unmyelinated fibers was markedly reduced. Schwann cell is of small size and its nucleus is rich in heterochromatine. $(\times 5,000)$. 
revealed MUPs of high amplitude, polyphasic, and of long duration in bilateral forearm and hand muscles, as well as fibrillation and fasciculation potentials in the bilateral extensor digitorum muscles.

\section{Morphological studies}

On January 31, 1984, a fascicular nerve biopsy was performed on the left sural nerve. The specimen was fixed with $2 \%$ glutaraldehyde in $0.12 \mathrm{M}$ phosphate buffer, post-fixed with $1 \%$ osmium tetroxide and dehydrated in an ascending alcohol series, embedded in epoxy-resin and cut transversely in sections of 1 $\mu \mathrm{m}$ thickness. The sections were stained with toluidine blue for light microscopy. Photographs of selected fascicules were prepared and enlarged to a final magnification of $\times 1,000$. The number and diameter distribution of myelinated fibers per square millimeter were calculated. Ultrathin sections were stained with uranyl acetate and lead citrate and examined by an electron microscope (JEM100S ; Nihon-Denshi, Tokyo). Unmyelinated axon diameters and density were obtained from electron micrograph montages with magnification of $\times 10,000$. Teased fiber analysis was impossible because of pausity of myelinated fibers.

Myelinated fibers were almost totally absent, and unmyelinated fibers were markedly reduced. The number of Schwann cell nuclei slightly increased (Fig. 1). Vascular changes, cell infiltration, onion bulb formation or amyloid deposit were not seen. The density of unmyelinated fibers was $3895 / \mathrm{mm}^{2}$ (normal controls : $35577 \pm 3455$, (mean \pm s.D.) $n=3$ ) and that of Schwann nuclei $3892 / \mathrm{mm}^{2}$ (normal controls : $3455 \pm 544, n=3$ ).

\section{Histamine skin reaction}

In October 1987, the axon reflex of cutaneous C-fibers was tested by an intracutaneous injection of $0.05 \mathrm{ml}$ of $0.1 \%$ histamine phosphate on the flexor surface of the forearm and the lateral surface of the leg. Because the flare tend to spread along the lymphatic channels, its width tangential to the longitudinal axis of limbs at $15 \mathrm{~min}$ after the injection was used for the evaluation. Flarewidth was $40 \mathrm{~mm}$ on both forearms, $30 \mathrm{~mm}$ on the left leg and $28 \mathrm{~mm}$ on the right leg. Mean values in 11 normal women were $45.3 \pm 7.3$ (mean \pm s.D.) $\mathrm{mm}$ on the forearm, and $42.5 \pm 5.0 \mathrm{~mm}$ on the leg (Table 1).

\section{Sudomotor functions}

In thermal sweating (TS) test, the patient in supine position was heated with electric blankets. The body temperature was monitored on the forehead with the deep body thermometer (Coretemp-CTM-204, probe-No : ME-PD5 ; Termo-Japan Company, Tokyo). Cholinergic postganglionic sudomotor function was tested under room temperature by two methods; sweating on the whole body was tested by a subcutaneous injection of $1 \%$ pilocarpine hydrochloride $(0.01 \mathrm{ml} / \mathrm{kg}$-body weight, PS), and focal cholinergic sweating was induced by an intracutaneous 
injection of $0.05 \mathrm{ml}$ of $5 \%$ acetylcholine chloride (Ach-S) on the forearm and leg. Sweating was qualitatively investigated with a modified Minor's colorimetric method by Sato and Takahashi (1980). A test-sheet for sweat detection was made in the following way. The $10 \%$ povidone solution was mixed with synthetized glue in volume ratio of $4: 1$, and spread on a transparent wrap-film for domestic use cut into $40 \mathrm{~cm} \times 100 \mathrm{~cm}$ in size. After it dried, the sheet was re-moistured slightly by an ultrasonic nebulizer, and a sheet of thin wafer was tightly attached on it. The test-sheets thus obtained could be used at any time. About 7-8 sheets

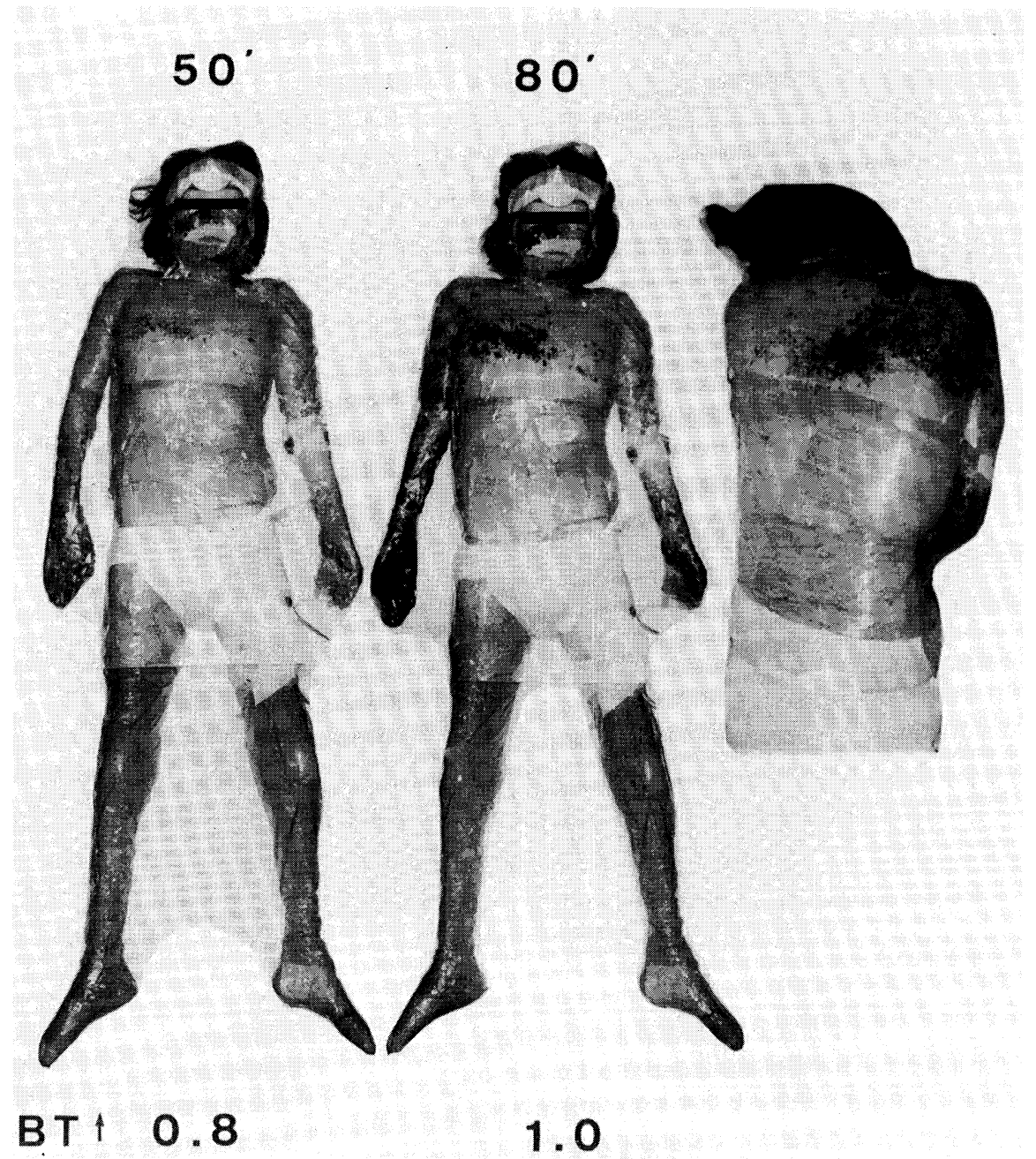

Fig. 2. Thermal sweating test shows band-like sweating area on the T4 dermatomal area of the right side. The face and the right upper limbs shows patchy sweating. Other parts of the body are practically anhidrotic. The numerals in top is time passed after start of heating. The body temperature before heating is $36.3^{\circ} \mathrm{C}$. 
were required to investigate the whole body sweating.

Local sweat volume was measured on the palmar surface of the forearm and on the lateral surface of the thigh by a capacitance hygrometer (HidrographAMU-2 ; Kyokuto-Denshi Compamy, Nagoya). For Ach-S, sweat volume during a sixty-second period starting at $1 \mathrm{~min}$ after the injection was used for the evaluation.

In September 1983, PS was qualitatively evaluated. Sweating appeared initially on the face and the region of T3-5 levels, then extended to the neck, upper chest and upper limbs. Fifty min after the injection, the regions above T67 sensory dermatomal level showed marked discoloration. Other parts were anhidrotic apart from scattered patchy or punctate sweating near the mid-line of the abdomen and the right thigh. In October 1987, TS appeared initially on the right $\mathrm{T} 4$ sensory dermatomal area. Then, patchy areas of sweating were seen on the upper limb and shoulder of the right side. Other parts were anhidrotic (Fig. 2 ).

Maximum sweat rates was $0.012 \mathrm{mg} / \mathrm{cm}^{2} / \mathrm{min}$ on the right forearm, $0.007 \mathrm{mg} /$ $\mathrm{cm}^{2} / \mathrm{min}$ on the left forearm, and no detectable sweating (less than $0.003 \mathrm{mg} / \mathrm{cm}^{2} /$

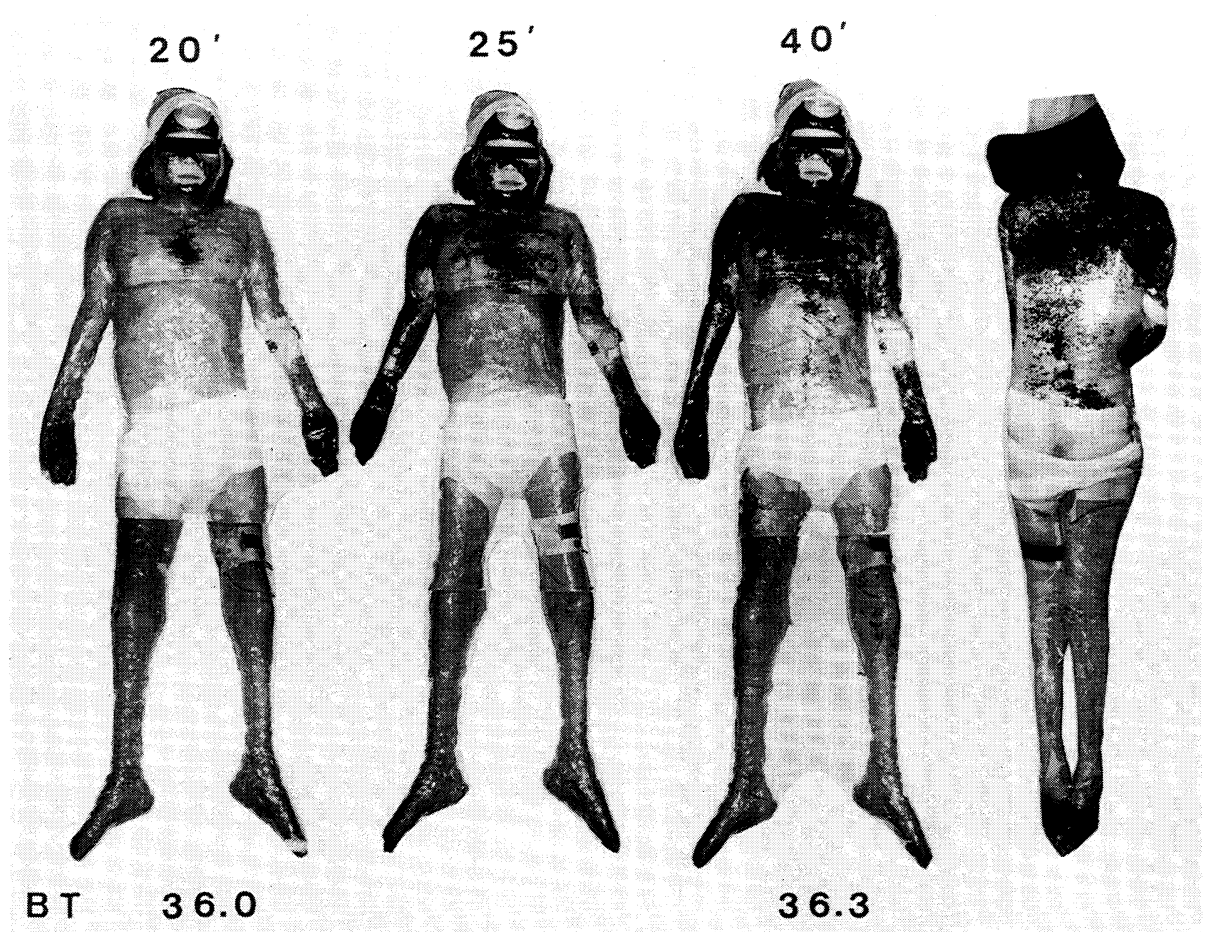

Fig. 3. Pilocarpine sweating test reveals symmetric sweating on the face, neck, and the chest. The upper limbs show patchy areas of sweating, especially on the left side. Areas below T5 are anhidrotic except for some sweating on the lower part of the back. Top numerals are time after the pilocarpine injection. 
TABLE 1. Results of histamine skin reaction and sudomotor function tests in the patient and in normal female controls

\begin{tabular}{|c|c|c|c|c|c|}
\hline & \multicolumn{2}{|c|}{ Forearm } & \multicolumn{2}{|c|}{ Lower limb } & \\
\hline & $\mathrm{R}$ & $\mathrm{L}$ & $\mathrm{R}$ & $\mathrm{L}$ & \\
\hline \multicolumn{6}{|l|}{ Histamine-flare (mm) } \\
\hline $\begin{array}{l}\text { Patient } \\
\text { (Controls, } n=11 \text { ) }\end{array}$ & $\begin{array}{l}40 \\
(45.3 \pm\end{array}$ & $\begin{array}{c}40 \\
7.3)\end{array}$ & $\begin{array}{l}30 \\
(42.5\end{array}$ & $\begin{array}{r}28 \\
\pm \quad 5.0)\end{array}$ & \\
\hline \multicolumn{6}{|c|}{ Thermal-S $\left(\mathrm{mg} / \mathrm{cm}^{2} / \mathrm{min}\right)$} \\
\hline $\begin{array}{l}\text { Patient } \\
\text { (Controls, } n=6 \text { ) }\end{array}$ & $\begin{array}{l}0.012 \\
(0.20 \pm\end{array}$ & $\begin{array}{r}0.007 \\
0.09)\end{array}$ & $\begin{array}{l}\text { N.E. } \\
(0.25\end{array}$ & $\begin{array}{l}\quad<0.003 \\
\pm \quad 0.02)\end{array}$ & $\begin{array}{l}\text { BT : } 37.3 \\
(\mathrm{BT}: 37.4 \pm 0.15)\end{array}$ \\
\hline \multicolumn{6}{|l|}{ Pilo-S (mg/ $\left.\mathrm{cm}^{2} / \mathrm{min}\right)$} \\
\hline Patient & N.E. & 0.008 & N.E. & $<0.003$ & $\mathrm{BT}: 36.4$ \\
\hline \multicolumn{6}{|l|}{ Ach-S $\left(\mathrm{mg} / \mathrm{cm}^{2} / \mathrm{min}\right)$} \\
\hline $\begin{array}{l}\text { Patient } \\
\text { (Controls, } n=13 \text { ) }\end{array}$ & $\begin{array}{l}0.021 \\
(0.195 \pm\end{array}$ & $\begin{array}{c}0.012 \\
0.083)\end{array}$ & $\begin{array}{l}0.004 \\
(0.224\end{array}$ & $\begin{array}{r}0.003 \\
+0.089)\end{array}$ & \\
\hline
\end{tabular}

Values are means \pm s.D.

Thermal-S, thermal sweating; Pilo-S, pilocarpine sweating; Ach-S, acetylcholine-induced focal sweating; BT, deep body temperature; $n$, number of subjects, N.E., not examined.

min) on left thigh with body temperature of $37.3^{\circ} \mathrm{C}$. The mean values in 6 normal women younger than 40 years were $0.20 \pm 0.09 \mathrm{mg} / \mathrm{cm}^{2} / \mathrm{min}$ on the forearm and $0.25 \pm 0.02 \mathrm{mg} / \mathrm{cm}^{2} / \mathrm{min}$ on the thigh with the body-temperature of $37.4 \pm 0.15^{\circ} \mathrm{C}$. In PS, sweating first appeared on cheeks and the median area of T3-4 level, and extended symmetrically across the whole face, neck and to the upper portion of the chest. The upper limbs also showed sweating more broadly than in the TS. Mid to lower portions of the back and lateral apsect of the right thigh showed punctate or pathy areas of reduced sweating. Other parts were anhidrotic (Fig. 3). Maximum sweat rate of the left forearm was $0.008 \mathrm{mg} / \mathrm{cm}^{2} / \mathrm{min}$, and no sweating was detected over the left thigh. (We have no quantitative data of PS on normal subjects). Ach-S was $0.021 \mathrm{mg} / \mathrm{cm}^{2} / \mathrm{min}$ on the right forearm, $0.012 \mathrm{mg} /$ $\mathrm{cm}^{2} / \mathrm{min}$ on the left forearm, $0.004 \mathrm{mg} / \mathrm{cm}^{2} / \mathrm{min}$ on the right leg, and $0.003 \mathrm{mg} /$ $\mathrm{cm}^{2} / \mathrm{min}$ on the left leg. Values in 13 normal women younger than 40 years were $0.195 \pm 0.083 \mathrm{mg} / \mathrm{cm}^{2} / \mathrm{min}$ on the forearm and $0.224 \pm 0.089 \mathrm{mg} / \mathrm{cm}^{2} / \mathrm{min}$ on the leg (Table 1).

\section{Pharmachological pupillary tests}

In November 1987, pupillary reactions to $4 \%$ cocaine, $1.25 \%$ epinephrine, $5 \%$ tyramine and $0.125 \%$ pilocarpine were tested on separate days under room-light. Two drops of each drug were applied with 5 minutes interval. The interval between the initial drop and final evaluation was $60 \mathrm{~min}$ for epinephrine and pilocarpine, $45 \mathrm{~min}$ for tyramine, and $90 \mathrm{~min}$ for cocaine. Pupillary diameters 
were 6.0 before and after cocaine administration. Epinephrine and tyramine dilated the diameters from 5.0 to $6.5 \mathrm{~mm}$ (dilatation ratio : $30 \%$ ), and from 5.0 to $7.5 \mathrm{~mm}(50 \%)$, respectively. Pilocarpine constricted the diameter from 5.5 to 2.0 $\mathrm{mm}$ (constriction ratio : $64 \%$ ) in the right eye, and from 5.5 to $1.5 \mathrm{~mm}(73 \%)$ in the left eye.

\section{Discussion}

The present patient had, since the age of 24, numerous episodes of CNS manifestations. The spatial and temporal dissemination of central nervous symptoms, the initial good recovery of visual loss with ensuing optic atrophy, and the increased CSF myelin basic protein are compatible with the diagnosis of MS (Poser et al. 1983)

The conspicuous feature of our patient was the involvement of the peripheral somatic and autonomic nervous systems. Clinical and electrophysiological investigations suggested a somatic nerve involvement, and the defective histamine reaction in lower limbs indicated the axonal degeneration of the C-fibers related to pain transmission (Foreman et al. 1983; Lembeck, 1983; Aronin et al. 1987). Provided that the sweat glands were intact, the results of sweating tests indicate, in addition to central sympathetic lesions, an extensive postganglionic impairment (Hyndman and Wolkin, 1941; MacMillan and Spalding 1969 ; Low et al. 1983). Pharmachological tests on pupils also supported the possible postganglionic autonomic impairments. Moreover, the sural nerve biopsy revealed severe axonal degeneration of myelinated and unmyelinated fibers. There were no findings indicative of demyelinating process or inflammation.

Subsquent to the studies by Hasson et al. (1958), several investigations have suggested that the association of MS and peripheral nerve involvement may not be exceptional (Hopf, 1965; Pollock et al. 1977; Hopf and Eysholdt; 1978; Weir et al. 1980). Hopf (1965) reported that the maximum conduction velocity of the ulnar nerve in 15 randomly selected MS patients was normal in all cases, but the difference in conduction velocity of fastest and slowest neurons was increased in 10 patients. The elongation of MCV had no relation with the duration after the onset of MS, and normalized after large dose steroid therapy. Hopf (1965) concluded that MS is a generalized disease in the initial stages and in acute exacerbations. Similarly, Pollock et al. (1977) studied the sural nerve from 10 MS-patients and 12 age-matched controls, among whom none had clinical evidence of peripheral neuropathy, and only one was severely disabled. They stated that the frequency of abnormal teased fibers was increased in MS.

In reported cases of MS with neuropathy, the peripheral lesions were of demyelinating or hypertrophic type (Schoene et al. 1977 ; Forrester and Lascelles, 1979 ; Lassmann et al. 1981; Ro et al. 1983; Tachi et al. 1985 ; de la Monte et al. 1986 ; Drake, 1987 ; Sanders and Lee 1987 ; Thomas et al. 1987). In our patient, however, the biopsied sural nerve showed severe axonal degeneration of both 
myelinated and unmyelinated fibers. She remained paraparetic and used a wheel-chair for 2.5 years before the initial admission to our hospital. She may have been subjected to traumatic or pressure-induced ischemic neuropathy. Lumsden (1970) described that, in the nerve trunks and spinal ganglia from 13 autopsied cases of MS, evidence of secondary Wallarian degeneration was common in the peripheral nerves of patients with gross limb deformities and occasional septic neuritis in the sciatic nerves relevant to bedsores. Miglietta and Lowenthal (1961) attributed mononeuritis found in 3 out of 54 MS-patients to a toxic, a nutritional or a pressure factor. Similar explanations may be possible for sural nerve changes in our case, but a pressure factor alone cannot explain the abnormal pupillary responses and extensive postganglionic anhidrosis involving the trunk and upper extremities.

The severe axonal degeneration of the peripheral nerve in our patient suggests that her neuropathy might be due to intoxication or malnutrition. Farthing et al. (1980) reported polyneuritis associated with azathioprine sensitivity reaction, and Eade et al. (1975) described polyneuropathy possibly associated with the use of indomethacin. However, our patient had taken $50 \mathrm{mg}$ of indomethacin on only two occasion, and no azathioprine before the sural nerve biopsy. Thus, it is difficult to attribute the patient's peripheral lesions to these drugs. The longterm carbamazepine therapy might cause a significant reduction of both motor and sensory conduction velocity (Traccis et al. 1983; Geraldini et al. 1984), but clinically overt neuropathy due to this drug has not been reported. As far as the information collected, she has not been administered other drugs currently known to cause peripheral neuropathy. The patient had slight but persistent anemia and reduced total protein. She had decubitus for a short period. Though the vitamin $\mathrm{B}$ complex and vitamin $\mathrm{C}$ were constantly given, the possibility of hyponutritional neuropathy could not be excluded in our patient. However, patients with MS in general, may be subjected to malnutrition in the late stage of the disease, but the neuropathy of axonal degeneration type has not been described even in autopsied cases of MS except for cases in Lumsden's review (1970).

Forrester and Lascelles (1979), and Sanders and Lee (1987) reported overt acute demyelinating polyradiculoneuritis (ADPN) associated with MS. Lassmann et al. (1981) reported a patient with acute MS who presented at the same time extremital atrophy and abnormal nerve conduction velocity. The patient died 12 weeks after the onset, and the autopsy revealed acute inflammatory demyelination in both the central and peripheral nervous systems. In ADPN, the inflammation in the peripheral nerves is not confined to their radicular parts and can be seen along their whole length, and there may be axonal degeneration in addition to segmental demyelination. Sometimes sympathetic nerves and ganglia may be severely involved (Matsuyama and Haymaker 1967; Arnason 1984). Similar associations might be possible in our patient, who, among numerous 
episodes of recurrent spinal impairments, often showed clinical signs and symptoms suggestive of peripheral nerve involvement. Though the clinical detection of neuropathy was difficult because of preexisting severe neurological deficits, the excerbation in March 1983 with weakness and hyporeflexisia of upper limbs, flaccid paralysis with normo-reflexia of lower limbs, and disappearance of Babinski's sign may be interpreted as an episode with peripheral involvement. However, the pausity of myelin ovoid and regeneration suggest the peripheral nerve involvement might be due not to a recent single episode, but to the repeated pathogenetic process.

The postganglionic sudomotor deficits seen in our patient may deserve some comments. There are only a few reports on sudomotor disturbances in MS patients (Noronha et al. 1968; Cartlidge 1972). Noronha et al. (1968) reported that 25 out of 60 MS-patients showed abnormal thermal sweating, and that two patients with total thermal anhidrosis failed to respond to intravenous pilocarpine in spite of positive muscarinic effects on other organs. However, clinical backgrounds of the two patients and pathogenetic mechanisms of their anhidrosis were not discussed.

In neonate or very young subjects, preganglionic lesion may cause transsynaptic alterations of the postganglionic system (Black and Mytilineou, 1976 ; Weinstein et al. 1980). Whether similar phenomenon may commonly occur in adult mammals is a matter of controversy (Cowan 1970). Though Hamlyn (1954) reported that the preganglionic section of the superior cervical ganglia in rabbits caused reduction of the mean cross-sectional area of the neurons and increased the connective tissue of the ganglion, there is few clinical evidence which clearly support the possibility of anterograde transsynaptic changes of the sympathetic ganglia in the adult. Thus, we speculate that the postganglionic impairment in our patient may not be secondary to more central lesions, but in parallel to peripheral lesion of the somatic nervous system. At present, however, we cannot elucidate the causative factors responsible for these impairments. The future physiological and pharmachological studies on sudomotor and other autonomic functions in patients with MS may help to evaluate the mode and frequency of peripheral nerve involvement in this disease.

\section{References}

1) Arnason, B.G.W. (1984) Acute inflammatory demyelinating polyradiculoneuropathies. In : Peripheral Neuropathy, edited by P.J. Dick, P.K. Thomas, E.H. Lambert \& R. Bunge, W.B. Saunders Company, Philadelphia, pp. 2050-2100.

2) Aronin, N., Leeman, S.E. \& Clements, R.S., Jr. (1987) Diminished flare response in neuropathic diabetic patients. Diabetes, 36, 1139-1143.

3) Black, I.B. \& Mytilineou, C. (1976) Trans-synaptic regulation of the development of end organ innervation by sympathetic neurons. Brain Res., 101, 503-521.

4) Cartlidge, N.E.F. (1972) Autonomic function in multiple sclerosis. Brain, 95, 661664 . 
5) Cowan, W.M. (1970) Anterograde and retrograde transneuronal degeneration in the central and peripheral nervous system. In: Contemporary Research Methods in Neuroanatomy, edited by W.J.H. Nauta \& S.O.E. Ebbesson, Springer-Verlag, Berlin, pp. 217-251.

6) de la Monte, S.M., Ropper, A.H., Dickersin, G.R., Harris, N.L., Ferry, J.A. \& Richardson, E.P., Jr. (1986) Relapsing central and peripheral demyelinating diseases. Unusual pathologic features. Arch. Neurol., 43, 626-629.

7) Drake, M.E., Jr. (1987) Peripheral neuropathy in multiple sclesosis. J. Natl. Med. Assoc., 79, 672-673.

8) Eade, O.E., Acheson, E.D., Cuthbert, M.F. \& Hawkes, C.H. (1975) Peripheral neuropathy and indomethacin. Br. Med. J., 2, 66-67.

9) Farthing, M.J.G., Coxon, A.Y. \& Sheaff, P.C. (1980) Polyneuritis associated with azathioprine sensitivity reaction. $B r$. Med. J., 280, 367

10) Foreman, J.C., Jordan, C.C., Oehme, P. \& Renner, H. (1983) Structure-activity relationships for some substance P-related peptides that cause wheal and flare reactions in human skin. J. Physiol., 335, 449-465.

11) Forrester, C. \& Lascelles, R.G. (1979) Association between polyneuritis and multiple sclerosis. J. Neurol. Neurosurg. Psychiatry, 42, 864-866.

12) Geraldini, C., Faedda, M.T. \& Sideri, G. (1984) Anticonvulsant therapy and its possible consequences on peripheral nervous system: A neurographic study. Epilepsia, 25, 502-505.

13) Hamlyn, L. H. (1954) The effect of preganglionic section on the neurons of the superior cervical ganglion in rabbits. J. Anat., 88, 184-191.

14) Hasson, J., Terry, R.D. \& Zimmerman, H.M. (1958) Peripheral neuropathy in multiple sclerosis. Neurology, 8, 503-510.

15) Hopf, H.C. (1965) Leitgeschwindigkeit motorischer Nerven bei der Multiplen Sklerose und unter dem Einfluß hoher Cortisonmedikation. Dtsch. Z. Nervenheilkd., 187, $522-526$.

16) Hopf, H.C. \& Eysholdt, M. (1978) Impaired refractory periods of peripheral sensory nerves in multiple sclerosis. Ann. Neurol., 4, 499-501.

17) Hyndman, O.R. \& Wolkin, J. (1941) The pilocarpine sweating test. I. A valid indicator on differentiation of preganglionic and postganglionic sympathectomy. Arch. Neurol. Psychiatry, 45, 992-1006.

18) Lassmann, H., Budka, H. \& Schnaberth, G. (1981) Inflammatory demyelinating polyradiculitis in a patient with multiple sclerosis. Arch. Neurol., 38, 99-102.

19) Lembeck, F. (1983) Sir Thomas Lewis's nocifensor system, histamine and substanceP-containing primary afferent nerves. Trends Neurosci., 6, 106-108.

20) Low, P.A., Caskey, P.E., Tuck, R.R., Fealey, R.D. \& Dyck, P.J. (1983) Quantitative sudomotor axon reflex test in normal and neuropathic subjects. Ann. Neurol., 14, 573-580.

21) Lumsden, C.E. (1970) The neuopathology of multiple sclerosis. In : Handbook of Neurology, Vol. 9, Multiple Sclerosis and Other Demyelinating Diseases, edited by P.J. Vinken \& G.W. Bruyn, North-Holland Publishing Company, Amsterdam, pp. 217-309.

22) MacMillan, A.L. \& Spalding, J.M.K. (1969) Human sweating responses to electrophoresed acetylcholine: A test of postganglionic sympathetic function. J. Neurol. Neurosurg. Psychiatry, 32, 155-160.

23) Matsuyama, H. \& Haymaker, W. (1967) Distribution of lesions in the Guillain-Barré syndrome, with emphasis on involvement of the sympathetic system. Acta Neuropathol., 8, 230-241.

24) Miglietta, O. \& Lowenthal, M. (1961) A study of peripheral nerve involvement in fifty-four patients with multiple sclerosis. Arch. Phys. Med. Rehab., 42, 573-578.

25) Noronha, M.J., Vas, C.J. \& Aziz, H. (1968) Autonomic dysfunction (sweating responses) in multiple sclerosis. J. Neurol. Neurosurg. Psychiatry, 31, 19-22 
26) Pollock, M., Calder, C. \& Allpress, S. (1977) Perpheral nerve abnormality in multiple sclerosis. Ann. Neurol., 2, 41-48.

27) Poser, C.M. (1987) The peripheral nervous system in multiple sclerosis. A review and pathogenetic hypothesis. J. Neurol. Sci., 79, 83-90.

28) Poser, C.M., Paty, D.W., Scheinberg, L., McDonald, W.I., Davis, F.A., Ebers, G.C., Johnson, K.P., Sibley, W.A., Silberberg, D.H. \& Tourtellotte, W.W. (1983) New diagnostic criteria for multiple sclerosis: Guideline for research protocols. Ann. Neurol., 13, 227-231.

29) Ro, Y.I., Alexander, C.B. \& Oh, S.J. (1983) Multiple sclerosis and hypertrophic demyelinating peripheral neuropathy. Muscle Nerve, 6, 312-316.

30) Sanders, E. A.C.M. \& Lee, K.D. (1987) Acute Guillain-Barré syndrome in multiple sclerosis. J. Neurol., 234, 128.

31) Sato, T. \& Takahashi, K. (1980) A simple method of general sweating test by use of wrap-film. Neurological Med., 13, 276-278. (Japanese)

32) Schoene, W.C., Carpenter, S., Behan, P.O. \& Geschwind, N. (1977) 'Onion bulb' formations in the central and peripheral nervous system in association with multiple sclerosis and hypertrophic polyneuropathy. Brain, 100, 755-773.

33) Tachi, N., Ishikawa, A., Tsuzuki, A. \& Minami, R. (1985) A case of childhood multiple sclerosis with peripheral neuropathy. Neuropediatrics, 16, 231-234.

34) Thomas, P.K., Walker, R.W.H., Rudge, P., Morgan-Hughes, J.A., King, R.H.M., Jacobs, J.M., Mills, K.R., Ormerod, I.E.C., Murray, N.M.F. \& McDonald, W.I. (1987) Chronic demyelinating peripheral neuropathy associated with multifocal central nervous system demyelination. Brain, 110, 53-76.

35) Traccis, S., Monaco, F., Sechi, G.P., Moglia, A. \& Mutani, R. (1983) Long-term therapy with carbamazepine: Effect on nerve conduction velocity. Eur. Neurol., 22, $410-416$.

36) Weinstein, J.M., Zweifel, T.J. \& Thompson, H.S. (1980) Congenital Horner's syndrome. Arch. Ophthalmol., 98, 1074-1078.

37) Weir, A.l., Hansen, S. \& Ballantyne, J.P. (1980) Motor unit potential abnormalities in multiple sclerosis: Further evidence for a peripheral nervous system defect. $J$. Neurol. Neurosurg. Psychiatry, 43, 999-1004. 